\title{
Oncocytic Schneiderian Papilloma
}

National Cancer Institute

\section{Source}

National Cancer Institute. Oncocytic Schneiderian Papilloma. NCI Thesaurus. Code C54345.

\begin{abstract}
A benign neoplasm with exophytic and endophytic growth arising from the lateral nasal wall or the paranasal sinuses. It is characterized by the proliferation of columnar cells with oncocytic features. Microcysts containing mucin and neutrophils are present in the epithelium. Clinical manifestations include nasal obstruction and epistaxis. Occasionally, it is associated with the development or presence of a carcinoma, usually squamous cell carcinoma.
\end{abstract}

